\title{
Introducing enhanced recovery after surgery protocol in pediatric surgery
}

\author{
Anna Modrzyk ${ }^{A-D}$, Michał Jerzy Pasierbek ${ }^{D, E}$, Wojciech Korlacki ${ }^{\mathrm{E}, \mathrm{F}}$, Andrzej Grabowski ${ }^{\mathrm{C}}$ \\ Department of Children's Developmental Defects Surgery and Traumatology, Medical University of Silesia, Zabrze, Poland \\ A - research concept and design; $B$ - collection and/or assembly of data; $C$ - data analysis and interpretation; \\ $D$ - writing the article; $E$ - critical revision of the article; $F$ - final approval of the article
}

Address for correspondence

Michał Jerzy Pasierbek

E-mail:michal.pasierbek@sum.edu.pl

Funding sources

None declared

Conflict of interest

None declared

Received on February 26, 2020

Reviewed on March 7, 2020

Accepted on May 1,2020

Published online on August 21, 2020

\section{Abstract}

Background. Enhanced recovery after surgery (ERAS) is a holistic perioperative care protocol created to improve treatment outcomes. Implementation of new rules radically changed the perioperative care of adult patients. The protocol refers to the preoperative, intraoperative and postoperative periods.

Objectives. To describe a novel pediatric ERAS protocol designed for reverse stoma surgery and to compare a group of patients with implemented ERAS protocol to a group of patients from pre-ERAS period.

Material and methods. A retrospective comparative review was performed which included 14 patients from pre-ERAS period (2016-2017) and 13 patients in the ERAS period (2018-2019). Total parenteral nutrition (TPN) time, time to oral fluid intake, time to regular diet, time to stooling, and length of stay (LOS) were analyzed.

Results. In the ERAS period, the LOS decreased from 8.64 to 6.08 days, time to oral fluid intake decreased from 4.36 to 1 postoperative day, time to regular diet decreased from 6.14 to 3.23 postoperative day. Total parenteral nutrition decreased from 5.14 in the pre-ERAS period to 1.69 days in the ERAS period. With the progress of implementation of ERAS protocol, TPN was gradually withdrawn.

Conclusions. The implementation of the pediatric ERAS in children undergoing reverse stoma surgery is safe, reduces patient's metabolic stress and improves treatment outcomes. However, further research is needed.

Key words: pediatric surgery, total parenteral nutrition, enhanced recovery after surgery, length of stay, enhanced recovery after surgery

Cite as

Modrzyk A, Pasierbek MJ, Korlacki W, Grabowski A.

Introducing enhanced recovery after surgery protocol

in pediatric surgery. Adv Clin Exp Med. 2020;29(8):937-942.

doi: $10.17219 /$ acem/121931

DOI

10.17219/acem/121931

Copyright

Copyright by Author(s)

This is an article distributed under the terms of the

Creative Commons Attribution 3.0 Unported (CC BY 3.0)

(https://creativecommons.org/licenses/by/3.0/) 


\section{Introduction}

In 1999, Henrik Kehlet described the first attempts to improve adult perioperative care for patients undergoing open sigmoidectomy. ${ }^{1}$ In this paper, Kehlet described various factors impacting the length of stay (LOS) and proposed a multimodal rehabilitation program, which helped to reduce LOS after colonic surgery from 5-10 days to 2 days without increasing complications. In further works, Kehlet indicated the importance of preoperative patient information, as well as thoracic epidural anesthesia in open colonic surgery. ${ }^{2}$ In 2001, members of the working group, including Olle Ljungqvist and Henrik Kehlet, analyzed many more research works in the field of perioperative care and "fast track" programs, and identified a few other factors in the patient's treatment which have an impact on surgical complications. ${ }^{3}$ The extended "fast track" program was formally named as enhanced recovery after surgery (ERAS) protocol. Such protocols have been adopted relatively slowly in both adult and pediatric surgery, and Kehlet in one of his recent works provides an interesting discussion about the reasons for that, ${ }^{4}$ with encouragement to move forward.

Enhanced recovery after surgery gathers a set of preoperative, intraoperative and postoperative guidelines. The core part of the protocol is aimed at maintaining physiologic homeostasis by reducing metabolic stress caused by a surgical procedure. ${ }^{5,6}$ Recently, ERAS protocol have been published not only for colorectal surgery, but also for many other adult procedures, such as cardiac surgery, gynecologic/oncology, lung and liver surgery, esophagectomy, breast reconstruction, major head and neck cancer surgery with free flap reconstruction, bariatric surgery, pancreaticoduodenectomy, radical cystectomy for bladder cancer, and gastrectomy. ${ }^{7}$

Many studies in the field of ERAS suggest that the protocol adopted for adult patients is feasible, safe and effective. ${ }^{8}$ So far, there have been few published works dealing with ERAS for children, and many of those are theoretical discussions.

In this paper, we presented a novel, pediatric enhanced recovery after surgery (pediatric ERAS) protocol implemented for children undergoing reverse stoma surgery at our department since January 2018.

\section{Material and methods}

\section{Study design}

Various types of elective procedures performed in our department in the pre-ERAS period were analyzed from January 2016 to December 2017 by a team of surgeons, anesthesiologists and nurses. Perioperative treatment was assessed and compared with ERAS protocol assumptions. A group of patients assigned for reverse stoma surgery was selected. This group had been treated with varying classic perioperative procedures, especially with respect to ERAS protocol, and therefore it was possible to perform a wide and thorough study of how various stages of ERAS impact the patient's overall convalescence.

A retrospective review was performed of 14 patients in the pre-ERAS period from January 2016 to December 2017 and 13 patients in the ERAS period from January 2018 to May 2019. In most cases, stoma was performed in the neonatal period, mainly as a result of necrotizing enterocolitis (NEC), anal atresia and meconium ileus (MI). The distribution of illnesses leading to stoma are shown in Fig. 1. The types of stoma are shown in Fig. 2

The parameters of total parenteral nutrition (TPN) time, time to oral fluid intake, time to regular diet, time to stool, and LOS were analyzed.

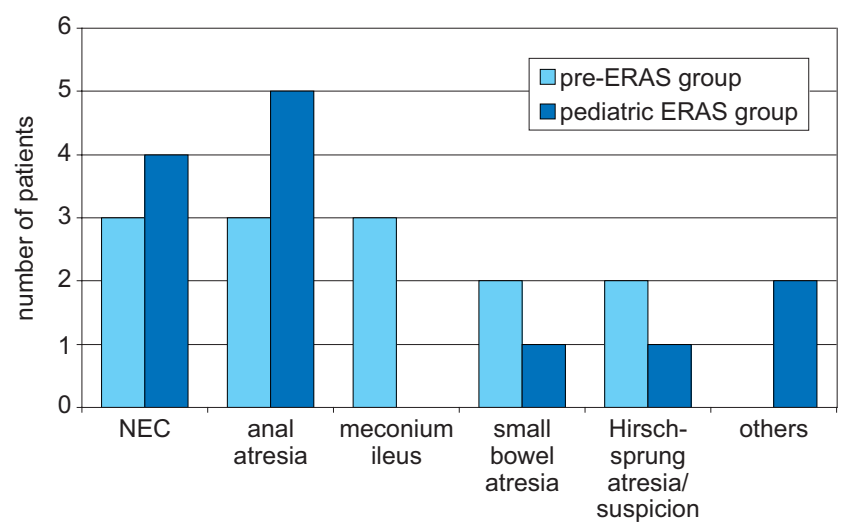

Fig. 1. Illnesses being reasons for performing stoma

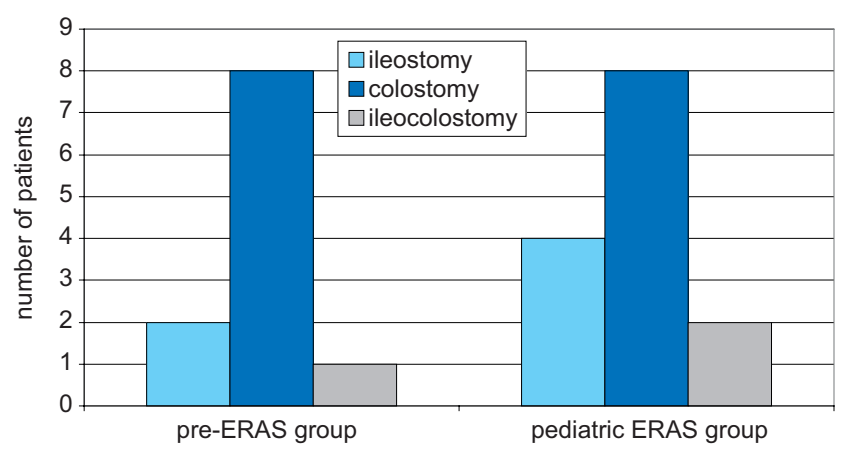

Fig. 2. Analyzed group of patients (reverse stoma surgery)

\section{Pediatric ERAS protocol development}

After the analyzed group of patients had been revised, the development of the ERAS protocol suitable for our patients was launched. Classic ERAS for adult patients was the reference; however, an evaluation of each stage of the original protocol was done, assessing the safeness and benefits for children, as well as the possibility of practical implementation in our hospital. As a result of this thorough process, pediatric ERAS consisting of 16 steps was prepared as shown in Table 1. 
Table 1. Comparison of pre-ERAS and pediatric ERAS procedures

\begin{tabular}{|c|c|c|}
\hline ERAS procedures & $\begin{array}{l}\text { Pre-ERAS } \\
\text { treatment }\end{array}$ & $\begin{array}{l}\text { Pediatric ERAS } \\
\text { treatment }\end{array}$ \\
\hline \multicolumn{3}{|c|}{ Preoperative } \\
\hline 1. Preadmission preparation & $\begin{array}{c}\text { not } \\
\text { included }\end{array}$ & included \\
\hline $\begin{array}{l}\text { 2. Oral nutrition support } 2 \text { weeks } \\
\text { in advance }\end{array}$ & $\begin{array}{l}\text { not } \\
\text { included }\end{array}$ & included \\
\hline 3. Zero-residue diet 3 days in advance & $\begin{array}{l}\text { not } \\
\text { included }\end{array}$ & included \\
\hline $\begin{array}{l}\text { 4. Intravenous antibiotics only } \\
\text { (cephalosporin } 3^{\text {rd }} \text { generation } \\
+ \text { metronidazole) }\end{array}$ & $\begin{array}{c}\text { not } \\
\text { included }\end{array}$ & included \\
\hline 5. No prolonged preoperative fasting & $\begin{array}{l}\text { not } \\
\text { included }\end{array}$ & included \\
\hline $\begin{array}{l}\text { 6. Supply of non-opiate preoperative } \\
\text { analgesic medications }\end{array}$ & included & included \\
\hline \multicolumn{3}{|c|}{ Intraoperative } \\
\hline $\begin{array}{l}\text { 7. Intraoperative tasks for } \\
\text { anesthesiologists }\end{array}$ & included & included \\
\hline 8. TAP-block & $\begin{array}{l}\text { not } \\
\text { included }\end{array}$ & not included \\
\hline $\begin{array}{l}\text { 9. Avoid nasogastric tubes and } \\
\text { peritoneal cavity drainage after } \\
\text { anastomosis }\end{array}$ & included & included \\
\hline 10. Early removal of urinary catheter & included & included \\
\hline \multicolumn{3}{|c|}{ Postoperative } \\
\hline 11. Avoid fluids and salt overload & $\begin{array}{l}\text { not } \\
\text { included }\end{array}$ & included \\
\hline $\begin{array}{l}\text { 12. Non-opioid analgesia for } \\
\text { postoperative pain management }\end{array}$ & included & included \\
\hline $\begin{array}{l}\text { 13. Early oral intake with clears } \\
\text { in the postoperative day } 0\end{array}$ & $\begin{array}{c}\text { not } \\
\text { included }\end{array}$ & included \\
\hline $\begin{array}{l}\text { 14. Early oral nutrition } \\
\text { in the postoperative day } 1\end{array}$ & $\begin{array}{l}\text { not } \\
\text { included }\end{array}$ & included \\
\hline 15. Early mobilization & included & included \\
\hline 16. Audit of compliance and outcomes & $\begin{array}{c}\text { not } \\
\text { included }\end{array}$ & included \\
\hline
\end{tabular}

TAP - transversus abdominis plane.

Some of the procedures were performed even before pediatric ERAS protocol. These are indicated in the $2^{\text {nd }}$ column in Table 1. According to the ERAS protocol, perioperative care can be improved only when protocol guidelines for each patient are implemented to their fullest and the importance of multi-specialist cooperation is taken into account. Intraoperative tasks for anesthesiologists consist of 5 recommendations.

Restrictive fluid therapy and avoiding sodium overloading helps prevent the most common complication after reverse stoma surgery, such as paralytic ileus. Maintaining normothermia reduces the risk of postoperative wound infection. The use of dexamethasone and ondansetron during surgery prevents postoperative nausea and vomiting (PONV). The last guideline recommends the use of multimodal analgesia, which together with regional anesthesia techniques, such as infiltration and transversus abdominis plane (TAP)-block, reduces the stress associated with surgical procedure. An additional limitation of opioids is reduced time to regaining correct bowel function.

\section{Protocol implementation}

The implementation of pediatric ERAS was methodologically and logistically challenging. Understanding the physiological base of the protocol was key in changing the rules of the patient's treatment, which had been practiced for years and considered as canonical in pediatric surgery.

Doctor-patient-parent conversation following ERAS Society recommendations was introduced and information materials about preoperative nutrition were also provided. For every ERAS patient, assessment of the nutritional status using body mass index (BMI) score, percentile meshes, and check of albumin level was performed. As part of preadmission assessment, morphology parameters (to exclude anemia) were also checked, and, if required, consultations with other specialists were ordered. With respect to non-prolonged preoperative fasting, zero-residue diet up to $6 \mathrm{~h}$ and supply of clears, including supply of preoperative oral carbohydrate liquid $(10 \mathrm{~mL} / \mathrm{kg}$ up to a maximum $200 \mathrm{~mL}$ up to $2 \mathrm{~h}$ before surgery) were allowed. Before preparations for surgery, all parents had agreed to undergo the pediatric ERAS protocol. The parents were also educated about discharge criteria, i.e., 100\% tolerance of regular diet and fluids, successful defecation, patient's mobilization adequate to age, and pain control with oral medications.

Pediatric ERAS protocol was started in January 2018. The 16 steps proposed for pediatric ERAS protocol are shown in Table 1. Gradually, the new 9 steps of pediatric ERAS were introduced, in addition to 6 procedures that had been performed thus far. Finally, 15 points were successfully implemented. The only procedure that we have not managed to introduce in the analyzed group is TAPblock regional anesthesia.

\section{Results}

The level of confidence for the procedures and the conviction that ERAS is safe for young patients have been improving with each patient along with surgeons' efficiency. Initially, 8 stages of the protocol were enabled, whereas for the last patients $14-15$ procedures were successfully introduced. The progress in introducing pediatric ERAS in our group of 13 patients is shown in Fig. 3. From the 13 planned reverse stoma surgeries, 12 were performed as scheduled. For 1 of the patients, pediatric ERAS preadmission preparation revealed microcytic anemia; therefore, oral treatment was applied, which delayed the operation. Once the patient's morphology parameters had improved, surgery was performed successfully. 


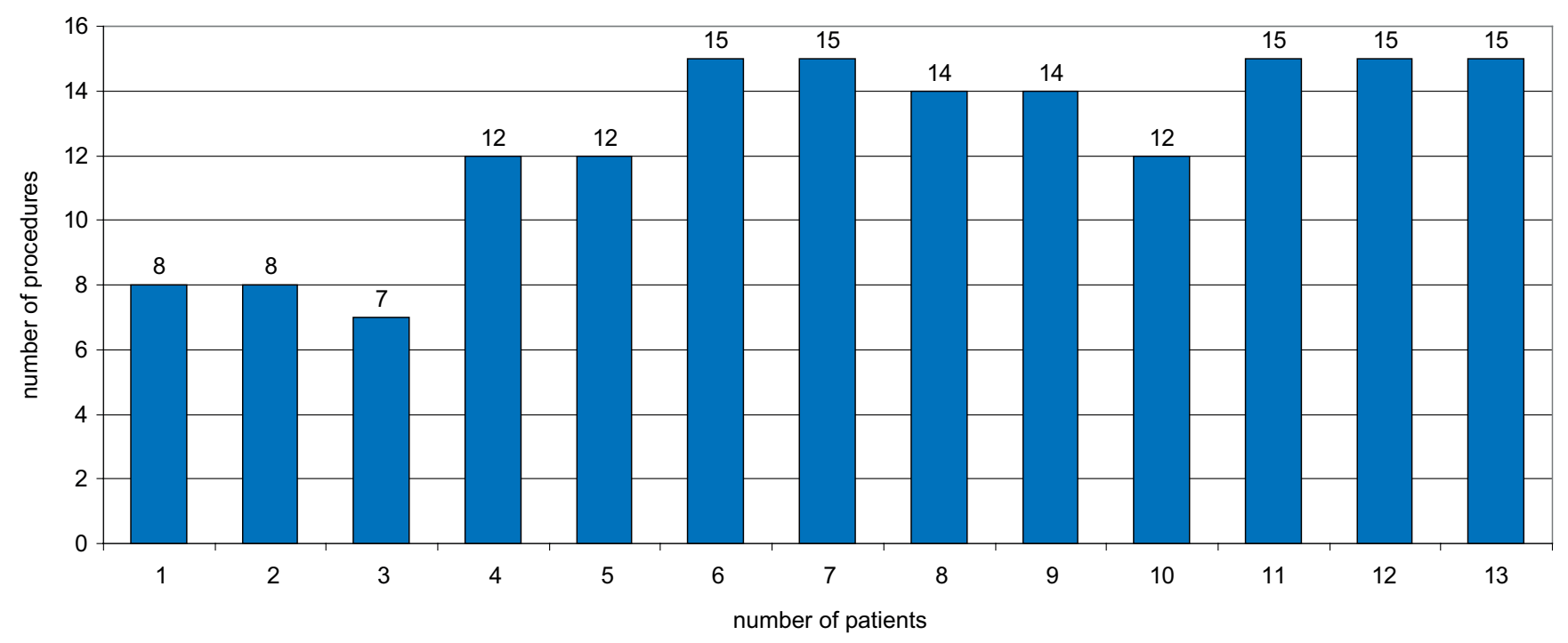

Fig. 3. Successfully introduced pediatric ERAS procedures per each pediatric patient

The average patient age in the pre-ERAS group was 0.9 years, with the age across the group ranging from 8 to 15 months. In the ERAS group, the average age was 2.05 years, with the youngest and oldest patient's age of 8 months and 8.17 years, respectively. The LOS in the ERAS group decreased from $8.64 \pm 2.4$ days to $6.08 \pm 2.6$ days in the period of 2016-2019. In the preERAS group, TPN lasted for $5.14 \pm 2.3$ days, oral fluid intake was introduced in $4.36 \pm 1.9$ postoperative day and full tolerance for regular diet was achieved in $6.14 \pm 2$ postoperative day. In the ERAS group, time to oral fluid intake was reduced to $1.0 \pm 1.5$ postoperative day and time to regular diet was reduced to $3.23 \pm 1.8$ postoperative days. Total parenteral nutrition decreased to $1.69 \pm 2.5$ days (averaged numbers with standard deviation (SD)). However, during the implementation of the pediatric ERAS protocol, TPN was gradually withdrawn, i.e., initially applied to 4 patients for 5.5 days on average, and then completely withdrawn for the remaining 10 patients (time of TPN $=0$ ). The withdrawal of TPN resulted in the introduction of a regular diet in the $2.22 \pm 1.1$ postoperative days and in shortening the average LOS to $5.33 \pm 1.2$ days. Furthermore, the reduction of time to stooling was observed, from $3.5 \pm 1.9$ to $2.23 \pm 0.9$ postoperative days (averaged numbers with SD). Comparative summary of the results achieved for the pre-ERAS and pediatric ERAS patients can be found in Table 2.

In the ERAS group, the only important complication was vomiting which occurred in 3 patients - in 2 patients after colostomy reversal (1 patient treated for Hirschsprung's disease and 1 with gastroschisis with colon atresia) vomiting was observed on the $1^{\text {st }}$ postoperative day, and in 1 girl after Bishop-Koop stoma reversal (treated for gastroschisis with short bowel syndrome/SBS/and partial parenteral nutrition) vomiting lasted for 4 postoperative days and stopped after erythromycin was introduced in prokinetic
Table 2. Pre-ERAS and pediatric ERAS treatment outcomes

\begin{tabular}{|l|c|c|}
\hline \multicolumn{1}{|c|}{ Observed parameter } & $\begin{array}{c}\text { Classic perioperative } \\
\text { treatment } \\
\text { (pre-ERAS) }\end{array}$ & $\begin{array}{c}\text { Pediatric } \\
\text { ERAS } \\
\text { treatment }\end{array}$ \\
\hline $\begin{array}{l}\text { Time to oral fluid intake } \\
\text { (postoperative day, } \pm \text { SD) }\end{array}$ & $4.36 \pm 1.9$ & $1.0 \pm 1.5$ \\
\hline $\begin{array}{l}\text { Time to regular diet } \\
\text { (postoperative day, } \pm \text { SD) }\end{array}$ & $6.14 \pm 2.0$ & $3.23 \pm 1.8$ \\
\hline $\begin{array}{l}\text { Time to stooling } \\
\text { (postoperative day, } \pm \text { SD) }\end{array}$ & $3.5 \pm 1.9$ & $2.23 \pm 0.9$ \\
\hline $\begin{array}{l}\text { Total parenteral nutrition time } \\
\text { (postoperative day, } \pm \text { SD) }\end{array}$ & $5.14 \pm 2.3$ & $1.69 \pm 2.5$ \\
\hline $\begin{array}{l}\text { Length of stay } \\
\text { (day, } \pm \text { SD) }\end{array}$ & $8.64 \pm 2.4$ & $6.08 \pm 2.6$ \\
\hline
\end{tabular}

doses. For the remaining ERAS patients, no complications were observed during hospitalization. None of the ERAS patients required readmission within 30 days and reoperation within 90 days.

\section{Discussion}

A thorough review of the current literature for pediatric ERAS can be found in research conducted by Shinnick et al. ${ }^{9}$ and Pearson et al. ${ }^{10}$ The former ${ }^{9}$ noticed that there is a paucity of high-quality literature evaluating pediatric ERAS, and observes in the review that in 5 studies regarding pediatric ERAS, the mean number of adopted elements was only 5.6 (the maximum 11 was presented in the review by Pearson et al. ${ }^{10}$ ) in comparison to over 23 procedures on average adopted in adults. From this perspective, our implementation of 15 procedures is a very good outcome. What is interesting, Pearson et al. ${ }^{10}$ also noticed that no implementation of preoperative carbohydrate load was an important exception from adult ERAS. This element 
was adopted in our study. Pearson et al. ${ }^{10}$ also referred to 2 studies which showed no reduction of costs. However, in our opinion, introducing pediatric ERAS with a reduction of LOS also reduced patient costs (less laboratory tests, less imaging examinations such as X-ray, ultrasound, no central venous catheter, less intravenous fluids and analgesic drugs). In terms of practical implementation, Short et al. ${ }^{11}$ in their interesting work presented the socalled pediatric-specific enhanced recovery protocol (ERP) developed for pediatric ileocecectomy, partial/total colectomy, proctectomy/J-pouch and pediatric ileostomy reversal. Based on available literature, the authors ${ }^{11}$ noticed that the assessment of individual elements used in ERAS (regional and non-opioid analgesia, the omission of a mechanical bowel preparation and usage of urinal catheters, early mobilization, the use of dexamethasone and ondansetron, early enteral nutrition) are safe in children, yet according to Rove et al. ${ }^{12}$ the synchronous study of entire protocols is of great interest. Also, Bernhard Haid et al. ${ }^{13}$ applied ERAS protocol for children undergoing augmentation and diversion surgery using small bowel, showing the protocol to be safe. However, applying ERAS protocols to infants, children and adolescents seems to be less challenging than in the case of neonates. Gibb and Crosby ${ }^{14}$ proposed neonatal ERAS guidelines, with new elements of care, for intestinal resection surgery.

We analyzed developed and implemented pediatric ERAS protocol for children undergoing reverse stoma surgery. Based on the treatment results, we observed a visible improvement in the general condition of the patients. During this short period of implementation of pediatric ERAS, vomiting was the only complication in 3 children. One patient with Hirschsprung's disease, after reversal colostomy, vomited once. In a nine-month old boy vomiting occurred after each attempt of oral fluid intake on the $1^{\text {st }}$ postoperative day; however, it lasted for 1 day and stopped after conservative treatment. In an eightmonth old girl with partial parenteral nutrition, undergoing reversal of Bishop-Koop stoma, vomiting lasted for 4 postoperative days. On the $5^{\text {th }}$ day, we introduced erythromycin in prokinetic doses, and the breakthrough was observed as she started to tolerate oral fluid intake and diet. However, we do not know what actually helped the return of correct bowel function, but we found out that last 2 patients mentioned above had a common feature, which was gastroschisis in the neonatal period. We suspected that the described problems were caused by the immaturity of the intestines. As mentioned above, none of the ERAS patients required readmission within 30 days and reoperation within 90 days, which confirmed the observations of Short et al. ${ }^{11}$

In our comparative study of 14 pre-ERAS and 13 pediatric ERAS patients, the following key parameters were observed: the length of stay, total parenteral nutrition time, time to oral fluid intake, time to regular diet, and time to defecation. For our team, early oral fluid intake and nutrition were the most important aspects. Time to oral fluid intake was reduced from $4.36 \pm 1.9$ days to $1.0 \pm 1.5$ day and time to regular diet from $6.14 \pm 2$ days to $3.23 \pm 1.8$ days, which was in agreement with other studies shown in the review by Shinnick et al. ${ }^{9}$ Furthermore, the length of stay was also decreased from $8.64 \pm 2.4$ days to $6.08 \pm 1.9$ days in our study, which was confirmed in other surveys mentioned in the aforementioned review. ${ }^{9}$ Historically, in our department, postoperative care was more conservative with zero diet lasting several days after surgery and intravenous hydration, as well as total parenteral nutrition applied to all the patients. What is more, children undergoing reverse stoma surgery quite often presented postoperative paralytic ileus, sometimes demanding diagnostic imaging to distinguish their condition from mechanical bowel obstruction. However, this was improved, as time to stooling decreased from $3.5 \pm 1.9$ days to $2.23 \pm 0.9$ days; however, we were unable to eliminate paralytic ileus in all ERAS patients. Nevertheless, we hope this can be achieved with greater experience gained with the protocol. Furthermore, the application of the pediatric ERAS enabled us to withdraw the parenteral nutrition, thereby allowing us to completely avoid the risk of complications caused by TPN.

Another important outcome of our study was considerable increase of patients and parents' comfort, as well as trust in medical staff. We observed that stress level of ERAS patients and their parents was significantly lower when compared with pre-ERAS patients, and they went through the overall hospitalization with much less trauma, which is particularly important for some patients undergoing multiple medical procedures due to serious disease. In our opinion, this lower stress and better comfort came from that fact that parents were well informed of and very engaged in the respective phases of the treatment; they knew how to prepare their children for surgery and had detailed knowledge of discharge criteria. Our conclusions in that the aspects of perioperative care were aligned with the outcomes of researched performed by Heiss and Raval, where they studied patient engagement to enhance recovery for children undergoing surgery. ${ }^{15}$

All the positive outcomes of pediatric ERAS described by the other authors ${ }^{10,11,13}$ together with our experience of handling unexpected postoperative complications give us confidence that this innovative protocol is feasible, safe and effective for children. Therefore, we are encouraged to continuously expand our skills in improving multimodal pain therapy. A good example of this is the application of TAP-block, which we hope to introduce in the near future, and which will further reduce the amount of oral and intravenous analgesic medicines. Our ultimate goal of using TAP-block is to accelerate the mobilization of patients after operations.

The limitation of our study was that the group of patients in our survey was very heterogeneous, which made the evaluation of every aspect difficult in a matter 
of unification. What is more, there is still room for improvement in antibiotic therapy. Specifically, our pediatric ERAS protocol did not incorporate guidelines for preoperative antibiotic prophylaxis. At the moment, full antibiotic therapy is employed. Furthermore, the other elements from adult ERAS, such as the use of insulin and thromboembolism prophylaxis, need more attention and further review. Thus, we are of the opinion that more studies in the field of ERAS applicable to children, as well as elaboration of clear and consistent rules of treatment dedicated for pediatric patients are needed.

\section{Conclusions}

We described the development and implementation of pediatric ERAS for children undergoing reverse stoma surgery at our Department of Children's Developmental Defects Surgery and Traumatology. The proposed pediatric ERAS protocol was feasible, safe and effective. Early introduction of oral fluid intake and nutrition in the implemented protocol allowed us to completely eliminate TPN in our treatment. Also, the time to stooling and LOS parameters were reduced. We considered the protocol outcomes to be positive, but more studies are needed in the field of pediatric ERAS.

\section{ORCID iDs}

Anna Modrzyk (1) https://orcid.org/0000-0001-5828-4171 Michał Jerzy Pasierbek (D) https://orcid.org/0000-0003-1215-2776

Wojciech Korlacki (D) https://orcid.org/0000-0002-2632-3567

Andrzej Grabowski (D) https://orcid.org/0000-0002-5162-3043

\section{References}

1. Kehlet $\mathrm{H}$, Mogen $\mathrm{T}$. Hospital stay of 2 days after open sigmoidectomy with a multimodal rehabilitation programme. Br J Surg. 1999;86(2): 227-230.

2. Kehlet H. Fast-track colorectal surgery. Lancet. 2008; 371(9615):791-793.

3. Kłęk S, Pędziwiatr M, Matłok M. Historia i motywy powstania protokołu ERAS, który zmieni opiekę okołooperacyjną. Med Prakt. 2014;4: 69-77.https://www.mp.pl/eras/wytyczne/103312,historia-i-motywypowstania-protokolu-eras-ktory-zmienil-opieke-okolooperacyjna. Accessed September 22, 2018.

4. Kehlet H. ERAS implementation: Time to move forward. Ann Surg. 2018;267(6):998-999.

5. Kehlet H. Multimodal approach to control postoperative pathophysiology and rehabilitation. Br J Anaesth. 1997;78(5):606-617.

6. Ljungqvist $O$, Jonathan E. Rhoads lecture 2011: Insulin resistance and enhanced recovery after surgery. J Parent Enteral Nutr. 2014;36(4): 389-398.

7. ERAS Society. List of Guidelines http://erassociety.org/guidelines/ list-of-guidelines/. Accessed September 15, 2019.

8. Liu VX, Rosas E, Hwang J, et al. Enhanced recovery after surgery program implementation in 2 surgical populations in an integrated health care delivery system. JAMA Surg. 2017;52(7):e171032.

9. Shinnick JK, Short HL, Heiss KF, Santore MT, Blakely ML, Raval MV. Enhancing recovery in pediatric surgery: A review of the literature. J Surg Res. 2016;202(1):165-176.

10. Pearson $\mathrm{KL}$, Hall NJ. What is the role of enhanced recovery after surgery in children? A scoping review. Pediatr Surg Int. 2017;33:43-51.

11. Short HL, Heiss KF, Burch K, et al. Implementation of an enhanced recovery protocol in pediatric colorectal surgery. J Pediatr Surg. 2017; 53(4):688-692.

12. Rove KO, Brockel MA, Saltzman AF, et al. Prospective study of enhanced recovery after surgery protocol in children undergoing reconstructive operations. J Pediatr Urol. 2018;14(3):252.

13. Haid B, Karl A, Koen M, Mottl W, Haid A, Oswald J. Enhanced recovery after surgery (ERAS) protocol, pediatric urologic augmentation and diversion surgery using small bowel. J Urol. 2018;200(5):1100-1106.

14. Gibb ACN, Crosby MA, McDiarmid C, et al. Creation of an enhanced recovery after surgery (ERAS) guideline for neonatal intestinal surgery patients: A knowledge synthesis and consensus generation approach and protocol study. BMJ Open. 2018;8(12):e02365.

15. Heiss KF, Raval MV. Patient engagement to enhance recovery for children undergoing surgery. Semin Pediatr Surg. 2018;27(2):86-91. 